\title{
Patient-Reported Outcome Measurement Information System (PROMIS) in Orthopaedic Trauma Research
}

\author{
Colin P. Sperring ${ }^{1, *}$, Nicholas C. Danford ${ }^{1}$, Bryan M. Saltzman ${ }^{2}$, Michael Constant ${ }^{1}$, \\ Nicholas J. Dantzker ${ }^{1}$, and David P. Trofa ${ }^{1}$ \\ ${ }^{1}$ Department of Orthopaedic Surgery, Columbia University Irving Medical Center/NY-Presbyterian Hospital, 622 West 168th Street, \\ PH 11-1130, New York, 10032 NY, USA \\ 2 Department of Orthopaedic Surgery, OrthoCarolina, 1915 Randolph Road, Charlotte, 28207 NC, USA
}

Received 26 March 2021, Accepted 15 May 2021, Published online 16 July 2021

\begin{abstract}
This review describes the development, advantages and disadvantages, and applications of the PatientReported Outcome Measurement Information System (PROMIS) in orthopaedic trauma. PROMIS is a useful tool for quantifying outcomes in orthopedic trauma. It allows measurement of outcomes across multiple domains while minimizing administration time. PROMIS also reliably identifies clinical, social, and psychological risk factors for poor outcomes across a variety of orthopaedic injuries and disease states. However, PROMIS lacks specificity for certain anatomic regions and validation for mental health outcomes. It also is limited by ceiling effects in certain active patient populations. Orthopaedic traumatologists should be familiar with PROMIS, as its use is increasing and it is a valuable tool that can aid in clinical decision making.
\end{abstract}

Key words: PROMIS, Trauma, Patient-reported outcomes, Computer-adaptive testing.

\section{Nomenclature}

List of non-PROMIS PROMs used in selected orthopaedic trauma studies

CSS

DASH

EQ-5D-3L

FAAM

FRAIL

IEQ

MEPS

OES

OSS

PCS

PF10

PHQ-2

PRWE

PSEQ-2

QuickDASH

SF-36

SMFA

TSK-11

Constant shoulder score

Disabilities of the arm, shoulder, and hand

3-level EuroQol 5 dimensions index

Foot and ankle ability measure

FRAIL questionnaire

Injustice experience questionnaire

Mayo elbow performance score

Oxford elbow score

Oxford shoulder score

Short form pain catastrophizing scale

10 -item physical functioning subscale from the SF/RAND-36

Short form patient health questionnaire for depression

The patient-rated wrist evaluation

Short form pain self-efficacy questionnaire

Disabilities of the arm, shoulder and hand questionnaire (11 items)

36-item short form 36 health survey

The 34-item SMFA dysfunction index were also collected

*Corresponding author: Cps2155@cumc. columbia.edu
UCLAAS

UCLASRS

VAS

University of California-Los Angeles activity scale

University of California-Los Angeles shoulder rating scale

Visual analog scale

\section{Introduction: Development of the Patient- Reported Outcome Measurement Information System (PROMIS)}

In 2004, PROMIS was developed by the National Institute of Health (NIH) to standardize patient-reported outcome measures (PROMs) [1]. PROMs refer to a variety of validated and standardized questionnaires that assess a patient's perception of his or her health and quality of life. Many different PROMs are used within orthopaedic surgery. Some measures summarize global physical, mental, and social functioning (for example, the Short-Form 36), while others are specific to various regions of the body (for example, the Oxford shoulder score, the Harris hip score) [2,3]. PROMs are used in research and are increasingly used for hospital administration, as they are tied to the quality of care measurement and reimbursement [3-6]. They can also be used to risk-stratify patients and thereby help with clinical decision-making [7].

In developing Patient-Reported Outcome Measurement Information System (PROMIS), the goal of the NIH was to 
create a standardized item bank that would measure patientreported outcomes (PROs), including physical, mental, and social health across many medical conditions and disease states, including disease and pathology of the musculoskeletal system $[1,8]$. They hypothesized that an accessible and reliable PROM tool would allow for a more efficient interpretation of clinical research and clinical outcomes when compared to the other PROMs [8].

Despite the growing use of PROMIS since its release in 2004, its role in orthopaedic trauma research remains unclear. In 2013, the Orthopaedic Trauma Association endorsed it as a beneficial tool in outcome research [9, 10]. Yet from 2014 to 2018, only two percent of orthopaedic trauma studies involving PROMs utilized PROMIS, possibly because of lack of familiarity with PROMIS among investigators [10]. Still, investigators currently face numerous challenges when using nonPROMIS PROMs. There is high variability among different PROMs with the same diagnosis $[11,12]$. In addition, the limited time for patients to complete these surveys has restricted the widespread use of PROMs [13]. Lastly, there is little consensus as to which PROM is best for specific injuries or disease states [14]. Together, these challenges suggest that widespread adoption of PROMIS may be beneficial. The purpose of this review is to provide an understanding of the development, validation, advantages, disadvantages, and application of the PROMIS in orthopaedic trauma.

\section{Understanding PROMIS: Content and outcome reporting theory}

As a dynamic tool, PROMIS is continually updated. As of 2020, there are eight main adult PROMIS domains split across three profiles (physical health, mental health, and social health) [1]. These domains include fatigue, pain intensity, pain interference, physical function, sleep disturbance, anxiety, depression, and the ability to participate in social roles and activities [1]. The PROMIS Physical Function and Pain Interference domains are of interest within orthopaedics. PROMIS offers two-item banks within Physical Function: Upper Extremity and Mobility [1]. PROMIS Upper Extremity measures the activity level of the upper extremities, while PROMIS Mobility measures physical mobility such as running, walking, and getting out of bed [1]. Pain Interference measures perceived consequences of pain on one's life, including the degree to which pain inhibits social, physical, emotional, and cognitive well-being [1]. With its vast array of domains and associated item banks, PROMIS offers over 300 different measures of PROs [1].

PROMIS is administered in two formats: short form and computerized adaptive testing (CAT) [1]. The short-form surveys consist of distinct, predetermined sets of questions administered electronically or by hand [1]. When creating a short form, the NIH only includes questions from the item bank which they deem to be the most relevant and efficient [15]. The reproducibility of the short form surveys allows for clinicians to continually ask the same set of questions at different time points in a patient's treatment, which may make it the preferred format for certain investigators [14].
The alternative to short-form, CAT, produces precise measurements using the minimum number of questions until a specified level of precision is achieved or a specified number of questions is answered [10]. CAT relies on item response theory to select the best follow up question based on a patient's answer to the previous question [16]. If a patient were to respond "No" to the question, "Are you able to walk one mile?", CAT would follow-up with a question to refine its accuracy, such as, "Are you able to walk one block?". This method of testing has been common in educational and psychological testing for the past 40 years, and research has shown that CAT produces similar results with fewer questions when compared to conventional testing methods like short-form [16]. Thus, CAT avoids the time burden that hampers the administration of other PROMs [16, 17].

Using item response theory, PROMIS scores individual questions based on the results of the overall population [14]. Unlike traditional scoring, each question is weighted separately, creating a scaled scoring system [14]. The results are presented as a T-score for which 50 is the average for the US population and 10 is the standard deviation [14]. By using T-scores, PROMIS attempts to avoid the floor and ceiling effects that complicate other PROMs [18]. Ultimately, PROMIS CAT provides validated, normalized, and precise measurements of physical function and pain for orthopaedic patients, while also measuring risk factors like anxiety and depression [19].

\section{Advantages and disadvantages of PROMIS in orthopaedic trauma}

\section{Upper extremity}

PROMIS Physical Function has been validated for different orthopaedic trauma patient populations [20, 21]. PROMIS Physical Function was validated for use in upper extremity trauma in 2015 [20]. In addition to its validation, the use of PROMIS within upper extremity orthopaedic trauma research has revealed its advantages and disadvantages (Table 1) [20, 22-24]. PROMIS Physical Function saves patients time compared to other PROMs, as demonstrated by Morgan et al. [20]. Additionally, when assessing patient perceptions on upper extremity trauma and its treatment, the Upper Extremity measure, an item bank within the PROMIS Physical Function domain, may be superior to full body PROMs, such as the 10-item Physical Function scale, the Quick-DASH, and the SMFA because of its excellent reliability, correlation with other PROMs, sensitivity to physical improvements over time, and decreased patient burden [22]. For many study populations within orthopaedic trauma of the upper extremity, PROMIS does not have floor or ceiling effects, which are weaknesses of certain PROMs [23].

Disadvantages of PROMIS Upper Extremity include a relative ceiling effect [23]. Gausden et al. reported that 28 percent of patients scored a 56.3 on PROMIS Upper Extremity, which was the highest score for their patient population [23]. This finding suggests PROMIS Upper Extremity is unable to stratify outcomes among more active patients. An additional 
Table 1. PROMIS and upper extremity injuries.

\begin{tabular}{|c|c|c|c|c|c|c|c|}
\hline Author & Year & $\begin{array}{l}\text { Study type and } \\
\text { level of evidence }\end{array}$ & \# of patients & PROMIS domain & Study injury & Other PROMs & Conclusions \\
\hline $\begin{array}{l}\text { Jayakumar } \\
\text { et al. [32] }\end{array}$ & 2020 & $\begin{array}{c}\text { Prospective } \\
\text { cohort study, II }\end{array}$ & 364 & $\begin{array}{l}\text { Upper extremity } \\
\text { (CAT) }\end{array}$ & $\begin{array}{l}\text { Distal radial } \\
\text { fracture }\end{array}$ & $\begin{array}{l}\text { PCS, PSEQ-2, } \\
\text { TSK-11, } \\
\text { QuickDASH, } \\
\text { PRWE, and } \\
\text { EQ-5D-3L }\end{array}$ & $\begin{array}{l}\text { Being retired, using } \\
\text { antidepressants, having } \\
\text { greater pain interference, and } \\
\text { greater pain catastrophizing } \\
\text { accounted for the majority of } \\
\text { variation of PROMIS Upper } \\
\text { Extremity at 6-9 months. }\end{array}$ \\
\hline $\begin{array}{l}\text { Bhashyam } \\
\text { et al. [33] }\end{array}$ & 2020 & $\begin{array}{l}\text { Retrospective } \\
\text { cohort study, III }\end{array}$ & 53 & $\begin{array}{l}\text { Physical function } \\
\text { (SF), upper } \\
\text { extremity (SF), } \\
\text { global mental, } \\
\text { global physical }\end{array}$ & $\begin{array}{l}\text { Distal humerus } \\
\text { fracture }\end{array}$ & QuickDASH & $\begin{array}{l}\text { PROMIS Psychological scores } \\
\text { were independently } \\
\text { associated with PROMIS } \\
\text { Physical Function scores and } \\
\text { correlated with both } \\
\text { PROMIS Physical Function } \\
\text { and Upper Extremity scores. }\end{array}$ \\
\hline $\begin{array}{l}\text { Bernstein } \\
\text { et al. [34] }\end{array}$ & 2019 & $\begin{array}{l}\text { Retrospective } \\
\text { cohort study, IV }\end{array}$ & 823 & $\begin{array}{l}\text { Pain interference } \\
\text { (CAT), physical } \\
\text { function (CAT), } \\
\text { depression (CAT) }\end{array}$ & $\begin{array}{l}\text { Distal radius } \\
\text { fracture, wrist or } \\
\text { hand sprain, tendon } \\
\text { rupture, traumatic } \\
\text { finger amputation, } \\
\text { or scaphoid fracture }\end{array}$ & & $\begin{array}{l}\text { Worse pain coping strategies } \\
\text { and lower levels of physical } \\
\text { functioning were } \\
\text { independently associated } \\
\text { with more frequent } \\
\text { orthopaedic office visits after } \\
\text { traumatic wrist or hand } \\
\text { injuries. }\end{array}$ \\
\hline $\begin{array}{l}\text { Jayakumar } \\
\text { et al. [24] }\end{array}$ & 2019 & $\begin{array}{l}\text { Prospective } \\
\text { cohort study, II }\end{array}$ & 734 & $\begin{array}{l}\text { Physical function } \\
\text { (CAT), upper } \\
\text { extremity (CAT) }\end{array}$ & $\begin{array}{c}\text { Shoulder, elbow or } \\
\text { wrist fracture }\end{array}$ & $\begin{array}{l}\text { QuickDASH, } \\
\text { OES, OSS, } \\
\text { PRWE, } \\
\text { EQ-5D-3L }\end{array}$ & $\begin{array}{l}\text { For patients with proximal } \\
\text { humerus and distal radius } \\
\text { fractures, PROMIS measured } \\
\text { quality of life instead of its } \\
\text { intended construct, patient } \\
\text { perception of physical } \\
\text { capability. }\end{array}$ \\
\hline $\begin{array}{l}\text { Gausden } \\
\text { et al. [23] }\end{array}$ & 2018 & $\begin{array}{c}\text { Prospective } \\
\text { cohort study, II }\end{array}$ & 174 & $\begin{array}{l}\text { Physical function } \\
\text { (CAT), upper } \\
\text { extremity (CAT), } \\
\text { pain interference } \\
\text { (CAT) }\end{array}$ & $\begin{array}{l}\text { Distal radius, } \\
\text { elbow, humeral } \\
\text { shaft, proximal } \\
\text { humeral, or } \\
\text { clavicular fracture }\end{array}$ & $\begin{array}{l}\text { VAS, DASH, } \\
\text { SF-36, UCLA } \\
\text { shoulder rating } \\
\text { scale, Constant } \\
\text { Shoulder score, } \\
\text { Mayo Elbow } \\
\text { Performance } \\
\text { score }\end{array}$ & $\begin{array}{l}\text { PROMIS Physical Function, } \\
\text { Upper Extremity and Pain } \\
\text { Interference have less } \\
\text { absolute floor and ceiling } \\
\text { effects when compared to } \\
\text { legacy PROMs. }\end{array}$ \\
\hline $\begin{array}{l}\text { Kaat } \\
\text { et al. [22] }\end{array}$ & 2017 & $\begin{array}{c}\text { Prospective } \\
\text { cohort study, II }\end{array}$ & 132 & $\begin{array}{l}\text { Physical function } \\
\text { (SF), upper } \\
\text { extremity (CAT) }\end{array}$ & $\begin{array}{l}\text { Upper extremity } \\
\text { fracture }\end{array}$ & $\begin{array}{l}\text { QuickDash, } \\
\text { PF-10, SMFA }\end{array}$ & $\begin{array}{l}\text { PROMIS Upper Extremity may } \\
\text { be superior to full body } \\
\text { PROMs because of its } \\
\text { excellent reliability, } \\
\text { correlation with legacy } \\
\text { PROMs, sensitivity to } \\
\text { physical improvements over } \\
\text { time, and decreased patient } \\
\text { burden. }\end{array}$ \\
\hline $\begin{array}{l}\text { Morgan } \\
\text { et al. [20] }\end{array}$ & 2015 & $\begin{array}{c}\text { Prospective } \\
\text { cohort study, II }\end{array}$ & 47 & $\begin{array}{c}\text { Physical function } \\
\text { (CAT) }\end{array}$ & $\begin{array}{l}\text { Proximal humerus } \\
\text { fracture }\end{array}$ & $\begin{array}{c}\text { Constant } \\
\text { Shoulder score, } \\
\text { DASH, SMFA }\end{array}$ & $\begin{array}{l}\text { PROMIS PF CAT correlates } \\
\text { well with legacy PROMS } \\
\text { with significantly shorter } \\
\text { time to complete. }\end{array}$ \\
\hline
\end{tabular}

disadvantage may be a lack of construct validity, the degree to which the questionnaire is measuring what it intends to measure [24]. Jayakumar et al. found that for patients with the proximal humerus and distal radius fractures, PROMIS measured quality of life instead of its intended goal, which was the patient perception of physical capability [24].

\section{Lower extremity}

PROMIS has also been validated for use in lower extremity orthopaedic trauma research [21]. As with upper extremity orthopaedic trauma, the use of PROMIS for lower extremity trauma has shown its advantages and disadvantages (Table 2) 
Table 2. PROMIS and lower extremity injuries

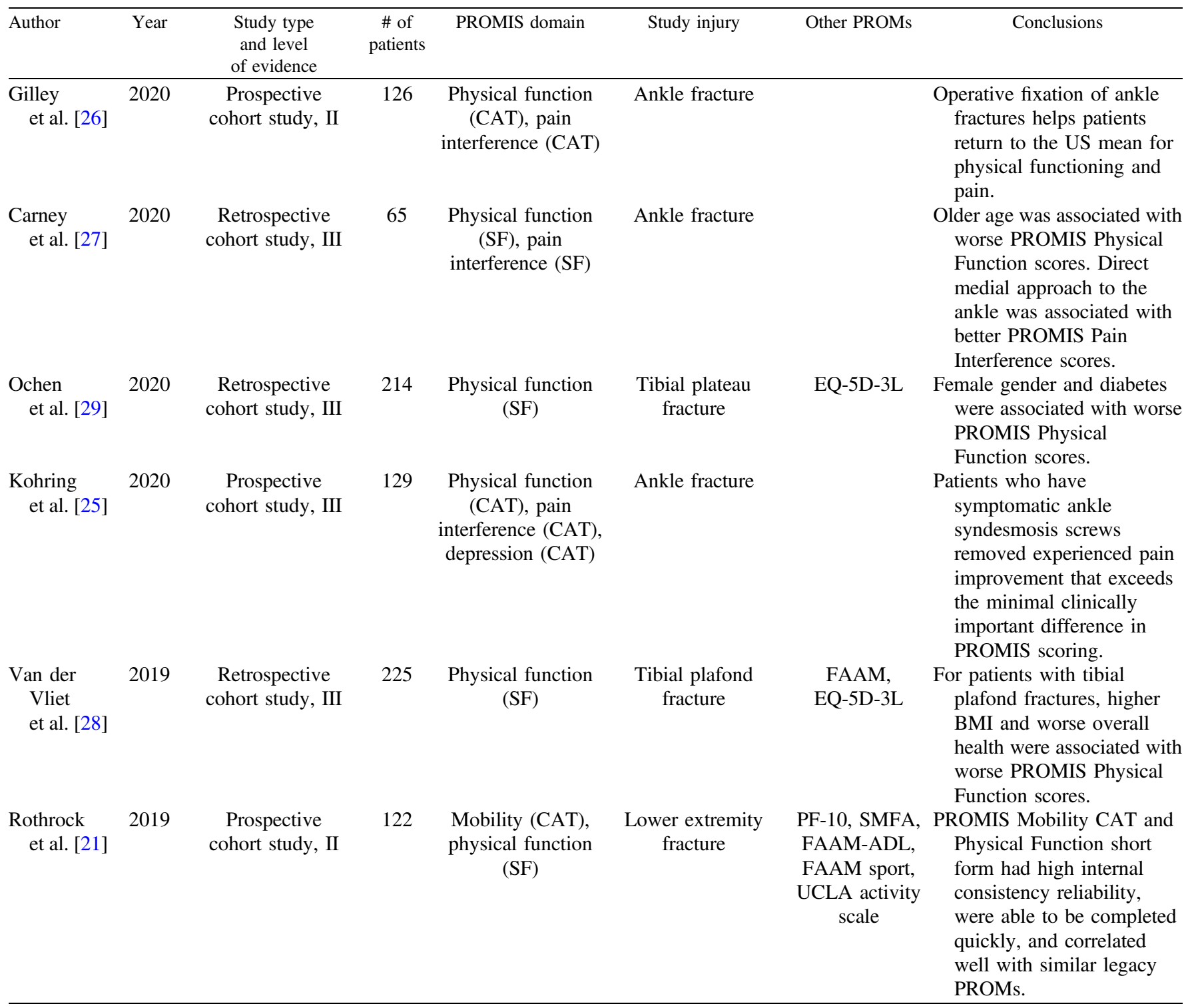

[21]. Rothrock et al. compared the PROMIS Mobility CAT and Physical Function short form to five other PROMs that measure outcomes for patients with lower extremity injuries [21]. They showed that both PROMIS domains measured their intended construct, patient perceptions of physical capability [21]. This is notably different from the observations of Jayakumar et al., who showed that PROMIS lacked construct validity for distal radius and proximal humerus fractures [24]. Rothrock et al. also noted that both PROMIS domains were able to be completed quickly and correlated well with similar legacy PROMs [21]. However, they did find that the PROMIS Physical Function short form had a relative ceiling effect that made it difficult to differentiate function among active patients [21]. The most strenuous activities measured by the questionnaire were exercises like carrying a bag of groceries and running errands, which are relatively undemanding for the active individual.
Thus the questionnaire was unable to detect improvements or differences in function among patients who are already very active [21].

\section{Outcomes for specific injury patterns}

PROMIS has also provided valuable insight into outcomes after specific injury patterns [25-29]. Kohring et al. used PROMIS Pain Interference to show that patients who have symptomatic ankle syndesmosis screws removed experienced pain improvement that exceeds the minimal clinically important difference in PROMIS scoring [25]. Gilley et al. used PROMIS Pain Interference and Physical Function to argue that operative fixation of ankle fractures reliably helps patients regain a level of function similar to the United States population mean [26]. 
Table 3. PROMIS - additional literature.

\begin{tabular}{|c|c|c|c|c|c|c|c|}
\hline Author & Year & $\begin{array}{l}\text { Study type } \\
\text { and level } \\
\text { of evidence }\end{array}$ & $\begin{array}{c}\text { \# of } \\
\text { patients }\end{array}$ & PROMIS domain & Study injury & Other PROMs & Conclusions \\
\hline $\begin{array}{l}\text { Alvarez- } \\
\text { Nebreda } \\
\text { et al. [31] }\end{array}$ & 2019 & $\begin{array}{c}\text { Prospective } \\
\text { cohort study, II }\end{array}$ & 273 & $\begin{array}{l}\text { Physical function (CAT), pain } \\
\text { interference (CAT) }\end{array}$ & $\begin{array}{l}\text { n Geriatric } \\
\text { trauma injury }\end{array}$ & FRAIL & $\begin{array}{l}\text { PROMIS Physical Function } \\
\text { scores completed by patients' } \\
\text { health care proxies were less } \\
\text { accurate for frail patients. }\end{array}$ \\
\hline $\begin{array}{l}\text { Shah } \\
\text { et al. [30] }\end{array}$ & 2019 & $\begin{array}{l}\text { Retrospective } \\
\text { cohort study, III }\end{array}$ & 333 & Physical function (CAT) & $\begin{array}{c}\text { Geriatric } \\
\text { trauma injury }\end{array}$ & & $\begin{array}{l}\text { Low-energy geriatric trauma } \\
\text { patients had worse functional } \\
\text { outcomes compared to the } \\
\text { high-energy geriatric trauma } \\
\text { patients after one or more } \\
\text { years post-injury. }\end{array}$ \\
\hline $\begin{array}{l}\text { Van Leeuwen } \\
\text { et al. [35] }\end{array}$ & 2016 & $\begin{array}{l}\text { Retrospective } \\
\text { cohort study, III }\end{array}$ & 124 & $\begin{array}{c}\text { Physical function (CAT), pain } \\
\text { intensity (SF) }\end{array}$ & $\begin{array}{l}\text { Any } \\
\text { traumatic } \\
\text { injury }\end{array}$ & $\begin{array}{l}\text { IEQ, PHQ-2, } \\
\text { PSEQ-2, PCS-4 }\end{array}$ & $\begin{array}{l}\text { Race, employment status, cause } \\
\text { of injury, and perception of } \\
\text { self-efficacy are all risk factors } \\
\text { for worse PROMIS Physical } \\
\text { Function scores, while } \\
\text { catastrophic thinking is a risk } \\
\text { factor for worse PROMIS Pain } \\
\text { Interference scores. }\end{array}$ \\
\hline
\end{tabular}

For patients who sustain supination-adduction type ankle fractures, older age was significantly associated with worse PROMIS Physical Function scores; additionally, the direct medial approach to the ankle, compared to the anteromedial and posteromedial approaches, was associated with better PROMIS Pain Interference scores [27].

For patients with tibial plafond fractures, a higher body mass index and an American Society of Anesthesiologist score of three or greater were associated with worse PROMIS Physical Function scores [28]. Finally, among patients who sustain bicondylar tibial plateau fractures, female gender, lower Health-related quality of life scores measured by 3-level EuroQol 5 dimensions, and diabetes were associated with worse PROMIS Physical Function scores [29]. These studies found similar associations for non-PROMIS PROMs [28, 29]. For example, a higher body mass index was associated with worse scores on the foot and ankle ability measure (FAAM) [28].

PROMIS has also has been used to study injuries in geriatric patients (Table 3) [30, 31]. Alvarez-Nebreda et al. revealed that PROMIS Physical Function scores of patients' health care proxies were less accurate for frail patients [31]. This is important as PROs of health care proxies may be used to assess outcomes for patients who are unable to complete PROMs [31].

\section{Capturing social and psychological influence on outcomes with PROMIS}

Outcome assessment using PROMIS has revealed the importance of social and psychological factors in the lives of patients [32-35]. Jayakumar et al. found that social and psychological factors such as being retired, using antidepressants, having greater pain interference, and greater pain catastrophizing explained the majority of physical limitation as measured by PROMIS Upper Extremity at 6-9 months following treatment of distal radius fractures [32]. As mentioned previously, pain interference is the perceived consequence of pain on one's life [1]. Pain catastrophizing is the tendency to magnify the threat of pain and the extent to which one feels helpless in its presence [36]. They argue that these social and psychological factors may be as or more important than clinical factors such as whether an operation was performed, injury severity, or radiographic outcome measurements [32]. They also found that PROMIS Pain Interference was the best predictor for upper extremity function limitation when compared to similar psychological questionnaires [32].

Bhashyam et al. found that PROMIS psychological scores were independently associated with PROMIS Physical Function scores among patients undergoing treatment for distal humerus fractures [33]. Additionally, using the PROMIS Global (mental) questionnaire, they showed that psychological scores correlated with both PROMIS Physical Function and Upper Extremity scores, highlighting the importance of mental health in orthopaedic trauma outcomes [33]. Using PROMIS Pain Interference and Physical Function, Bernstein et al. found that worse pain coping strategies were independently associated with more frequent orthopaedic office visits after traumatic wrist or hand injuries [34].

Van Leeuwen et al. used other PROMS (injustice experience questionnaire, short form pain self-efficacy questionnaire, short form patient health questionnaire for depression, and short form pain catastrophizing scale) to assess pain, depression, perceived injustice, and catastrophic thinking, and compared those scores to PROMIS Physical Function and Pain Interference scores [35]. When controlling for other variables, they found that Caucasian race, employed work status, cause of injury other than sports, motor vehicle crash or fall, and higher levels of self-efficacy were positively associated with improved PROMIS Physical Function scores, while less catastrophic thinking was associated with improved PROMIS Pain Interference scores [35]. Together, these data emphasize the influence 
of mental health and social support on orthopaedic trauma outcomes [32-35].

Despite the growing use of PROMIS as a tool to measure perceptions of physical function and pain within orthopaedic trauma, researchers continue to use non-PROMIS PROMs to measure mental health $[32,35]$. Thus, the PROMIS Mental Health profile, and its domains like PROMIS Emotional Distress and Self-Efficacy, require further validation among orthopaedic trauma researchers.

\section{Conclusion and future directions}

Within orthopaedic trauma, PROMIS has the major strengths of quick administration, reduced floor and ceiling effects, and a computer-adaptive model for testing [1, 20, 22, 23]. PROMIS can reliably identify clinical, social, and psychological risk factors for poor outcomes. [25-29, 32-35]. Its weaknesses are lack of specificity for certain body parts, its lack of validation for mental health outcomes, and its ceiling effect in certain active patient populations $[23,32,35]$. Future research will be directed toward further validation of PROMIS for specific injuries and body regions as well as the incorporation of the mental health profile. PROMIS may also benefit from including additional questions that would stratify outcomes among more active patients. The use of PROMIS is increasing and therefore familiarity with it will help the orthopaedic trauma surgeon in the interpretation of research and clinical decision making.

\section{Declarations of interest}

None. This research did not receive any specific grant from funding agencies in the public, commercial, or not-for-profit sectors.

\section{References}

1. National Institute of Health, HealthMeasures. Available at http://www.healthmeasure.net. (Accessed 05 July 2020).

2. Ayers DC (2017) Implementation of patient-reported outcome measures in total knee arthroplasty. J Am Acad Orthop Surg 25, S48-S50.

3. Ozaki Y, Baba T, Homma Y, Ochi H, Watari T, Banno S, Matsumoto M, Kaneko K (2018) Posterior versus direct anterior approach in total hip arthroplasty: Difference in patient-reported outcomes measured with the Forgotten Joint Score-12. Sicot-J 4, 54.

4. Ayers DC, Zheng H, Franklin PD (2013) Integrating patientreported outcomes into orthopaedic clinical practice: Proof of concept from FORCE-TJR. Clin Orthop Relat Res 471, 34193425.

5. MacCormick AP, Sharma H (2018) Does the severity of pain correlate with severity of functional disability? Factors influencing "patient reported outcome measures" in spinal patients. Sicot-J 4, 43.

6. Said HG, Masoud MA, Morsi MMA-H, El-Assal MA (2019) Outcomes of hip arthroscopy for femoroacetabular impingement: The effect of morphological type and chondrolabral damage. Sicot-J 5, 16.
7. Weinberg DS, Narayanan AS, Boden KA, Breslin MA, Vallier HA (2016) Psychiatric illness is common among patients with orthopaedic polytrauma and is linked with poor outcomes. J Bone Joint Surg - Am 98, 341-348.

8. Cella D, Yount S, Rothrock N, Gershon R, Cook K, Reeve B, Ader D, Fries JF, Bruce B, Rose M (2007) The Patient-Reported Outcomes Measurement Information System (PROMIS): Progress of an NIH roadmap cooperative group during its first two years. Med Care 45, S3-S11.

9. Orthopedic Trauma Association (2013) Symposium 1: Evaluating outcomes in the 21st century. In: Orthopaedic Trauma Association Annual Meeting, October 9-12, Phoenix, AZ.

10. O'Hara NN, Richards JT, Overmann A, Slobogean GP, Klazinga NS (2019) Is PROMIS the new standard for patientreported outcomes measures in orthopaedic trauma research? Injury 51, S43-S50.

11. Cella D, Gershon R, Lai JS, Choi S (2007) The future of outcomes measurement: Item banking, tailored short-forms, and computerized adaptive assessment. Qual Life Res 16, 133-141.

12. Makhni EC, Padaki AS, Petridis PD, Steinhaus ME, Ahmad CS, Cole BJ, Bach BR (2015) High variability in outcome reporting patterns in high-impact ACL literature. J Bone Joint Surg - Am 97, 1529-1542.

13. Schamber EM, Takemoto SK, Chenok KE, Bozic KJ (2013) Barriers to completion of patient reported outcome measures. J Arthrop 28, 1449-1453.

14. Makhni EC, Meadows M, Hamamoto JT, Higgins JD, Romeo AA, Verma NN (2017) Patient Reported Outcomes Measurement Information System (PROMIS) in the upper extremity: The future of outcomes reporting? J Shoulder Elbow Surg 26, 352-357.

15. Rose M, Bjorner JB, Becker J, Fries JF, Ware JE (2008) Evaluation of a preliminary physical function item bank supported the expected advantages of the Patient-Reported Outcomes Measurement Information System (PROMIS). J Clin Epidemiol 61, 17-33.

16. Cook KF, Choi SW, Crane PK, Deyo RA, Johnson KL, Amtmann D (2008) Letting the cat out of the bag: Comparing computer adaptive tests and an 11-item short form of the rolandmorris disability questionnaire. Spine 33, 1378-1383.

17. Rebollo P, Castejón I, Cuervo J, Villa G, García-Cueto E, DíazCuervo H, Zardaín PC, Muñiz J, Alonso J (2010) Validation of a computer-adaptive test to evaluate generic health-related quality of life. Health Qual Life Outcome 8, 1-8.

18. Pilkonis PA, Yu L, Dodds NE, Johnston KL, Maihoefer CC, Lawrence SM (2014) Validation of the depression item bank from the Patient-Reported Outcomes Measurement Information System $\left(\right.$ PROMIS $^{\circledR}$ ) in a three-month observational study. J Psychiatr Res 56, 112-119.

19. Riley WT, Pilkonis P, Cella D (2011) Application of the national institutes of health patient-reported outcome measurement information system (PROMIS) to mental health research. J Ment Health Policy Econ 14, 201.

20. Morgan JH, Kallen MA, Okike K, Lee OC, Vrahas MS (2015) PROMIS physical function computer adaptive test compared with other upper extremity outcome measures in the evaluation of proximal humerus fractures in patients older than 60 years. J Orthop Trauma 29, 257-263.

21. Rothrock NE, Kaat AJ, Vrahas MS, O'Toole RV, Buono SK, Morrison S, Gershon RC (2019) Validation of PROMIS physical function instruments in patients with an orthopaedic trauma to a lower extremity. J Orthop Trauma 33, 377-383. 
22. Kaat AJ, Rothrock NE, Vrahas MS, O'Toole RV, Buono SK, Zerhusen T, Gershon RC (2017) Longitudinal validation of the PROMIS physical function item bank in upper extremity trauma. J Orthop Trauma 31, e321-e326.

23. Gausden EB, Levack AE, Sin DN, Nwachukwu BU, Fabricant PD, Nellestein AM, Wellman DS, Lorich DG (2018) Validating the Patient Reported Outcomes Measurement Information System (PROMIS) computerized adaptive tests for upper extremity fracture care. J Shoulder Elbow Surg 27, 1191-1197.

24. Jayakumar P, Teunis T, Vranceanu A-M, Lamb S, Williams M, Ring D, Gwilym S (2019) Construct validity and precision of different patient-reported outcome measures during recovery after upper extremity fractures. Clin Orthop Relat Res 477, 2521-2530.

25. Kohring JM, Greenstein A, Gorczyca JT, Judd KT, Soles G, Ketz JP (2020) Immediate improvement in physical function after symptomatic syndesmotic screw removal. J Orthop Trauma 34, 327-331.

26. Gilley J, Bell R, Lima M, Butler B, Barrett JE, Patel M, Kadakia AR (2020) Prospective patient reported outcomes (PRO) study assessing outcomes of surgically managed ankle fractures. Foot Ankle Int 41, 206-210.

27. Carney J, Ton A, Alluri RK, Grisdela P, Marecek GS (2020) Complications following operative treatment of supinationadduction type II (AO/OTA 44A2.3) ankle fractures. Injury 51, 1387-1391.

28. van der Vliet QMJ, Ochen Y, McTague MF, Weaver MJ, Hietbrink F, Houwert RM, Leenen LPH, Heng M (2019) Longterm outcomes after operative treatment for tibial pilon fractures. OTA Int 2, e043.

29. Ochen Y, Peek J, McTague MF, Weaver MJ, van der Velde D, Houwert RM, Heng M (2020) Long-term outcomes after open reduction and internal fixation of bicondylar tibial plateau fractures. Injury 51, 1097-1102.

30. Shah J, Titus AJ, O'Toole RV, Sciadini MF, Boulton C, Castillo R, Breazeale S, Schoonover C, Berger P, Gitajn IL (2019) Are geriatric patients who sustain high-energy traumatic injury likely to return to functional independence? J Orthop Trauma 33, 234-238.

31. Alvarez-Nebreda ML, Heng M, Rosner B, McTague M, Javedan H, Harris MB, Weaver MJ (2019) Reliability of proxy-reported patient-reported outcomes measurement information system physical function and pain interference responses for elderly patients with musculoskeletal injury. J Am Acad Orthop Surg 27, e156-e165.

32. Jayakumar P, Teunis T, Vranceanu AM, Lamb S, Ring D, Gwilym S (2020) Early psychological and social factors explain the recovery trajectory after distal radial fracture. J Bone Joint Surg 102, 788-795.

33. Bhashyam AR, Ochen Y, van der Vliet QMJ, Leenen LPH, Hietbrink F, Houwert RM, Dyer GSM, Heng M (2020) Association of patient-reported outcomes with clinical outcomes after distal humerus fracture treatment. JAAOS Glob Res Rev 4, e1900122.

34. Bernstein DN, Crijns TJ, Mahmood B, Ring D, Hammert WC (2019) Patient characteristics, treatment, and presenting PROMIS scores associated with number of office visits for traumatic hand and wrist conditions. Clin Orthop Relat Res 477, 2345-2355.

35. Van Leeuwen WF, Van Der Vliet QMJ, Janssen SJ, Heng M, Ring D, Vranceanu AM (2016) Does perceived injustice correlate with pain intensity and disability in orthopaedic trauma patients? Injury 47, 1212-1216.

36. Quartana PJ, Campbell CM, Edwards RR (2009) Pain catastrophizing: A critical review. Expert Rev Neurother 9, 745-758.

Cite this article as: Sperring CP, Danford NC, Saltzman BM, Constant M, Dantzker NJ \& Trofa DP (2021) Patient-Reported Outcome Measurement Information System (PROMIS) in Orthopaedic Trauma Research. SICOT-J 7, 39 